\title{
P027: Semmelweis versus C. difficile: efficacy of chlorinated lime and other hand hygiene interventions
}

\author{
S Edmonds ${ }^{1 *}$, C Zapka $^{1}$, J Rutter ${ }^{1}$, C Fricker ${ }^{1}$, J Arbogast ${ }^{1}$, D Macinga ${ }^{1}$, R McCormack ${ }^{2}$ \\ From 2nd International Conference on Prevention and Infection Control (ICPIC 2013) \\ Geneva, Switzerland. 25-28 June 2013
}

\section{Introduction}

Clostridium difficileinfection is a significant issue in healthcare facilities, and proper hand hygiene is recommended to help prevent $C$. difficile transmission. It is known that alcohol based-handrubs are ineffective at killing $C$. difficile spores and recent studies demonstrate that the efficacy of hand washing is limited.

\section{Objectives}

The objective of this study was to evaluate several aggressive chemistries including chlorinated lime (the Semmelweis hand disinfection procedure) for reduction of $C$. difficile spores.

\section{Methods}

A modification of the ASTM method E1174 was used to evaluate $C$. difficile spore removal and inactivation. Approximately $1 \times 10^{6}$ spores of non-toxigenic C. difficile ATCC \#700057 were distributed onto the palms of subject's hands. A series of hand hygiene procedures were evaluated including a 30-second non-antimicrobial handwash and a 5 minute hand disinfection procedure with a scrub brush using $4 \%$ chlorinated lime, $2000 \mathrm{ppm}$ peracetic acid, or 1000 ppm acidified bleach. $\log _{10}$ reductions from baseline for each product were compared using ANOVA and post-hoc analysis $(\mathrm{P}<0.05)$ to identify statistically significant differences.

\section{Results}

The handwash, acidified bleach, peracetic acid, and chlorinated lime achieved $\log _{10}$ reductions of $0.66,0.79$, 1.64 , and 2.45 , respectively. Although $\log _{10}$ reductions were low, those for chlorinated lime and peracetic acid were statistically superior to acidified bleach and the non-antimicrobial handwash.

\section{Conclusion}

These data further reinforce that elimination of $C$. difficile spores from hands is very difficult. The two best chemistries, peracetic acid and chlorinated lime, still only achieved $\log$ reductions of $<2.5 \log _{10}$, despite aggressive and lengthy application procedures not feasible for healthcare workers. These data reinforce the need for contact precautions including gloving when caring for a C. difficile infected patient; and the importance of cleaning and disinfection to reduce environmental spore contamination. Further research is needed to identify hand hygiene approaches to effectively eliminate $C$. difficile from hands and to reduce patient safety risk.

\section{Disclosure of interest}

None declared.

\section{Author details \\ ${ }^{1}$ GOJO Industries, Inc, Akron, OH, USA. ${ }^{2}$ BioScience Laboratories, Inc., Bozeman, MT, USA.}

Published: 20 June 2013 